\title{
Mutational and expressional analysis of MLL genes in gastric and colorectal cancers with microsatellite instability
}

\author{
E. M. JE $E^{1, *}$, S. H. LEE $2, *$, N. J. YOO ${ }^{1}$, S. H. LEE LE, $^{1,3 *}$
}

${ }^{1}$ Department of Pathology, College of Medicine, The Catholic University of Korea, Seoul, Korea; ${ }^{2}$ Department of Hospital Pathology, College of Medicine, The Catholic University of Korea, Seoul, Korea; ${ }^{3}$ Research Center for Genome Polymorphism, College of Medicine, The Catholic University of Korea, Seoul 137-701, Korea

${ }^{*}$ Correspondence: suhulee@catholic.ac.kr

${ }^{*}$ Contributed equally to this work.

Received July 19, 2012/ Accepted September 24, 2012

\begin{abstract}
$M L L$ genes encode histone methyltransferases that are required for proper expression of a variety of genes. The pathologic implications of $M L L$ genes have been studied not only in leukemias, but also in some solid cancers. We found in a public database that $M L L, M L L 2, M L L 3, M L L 4$ and MLL5 genes had mononucleotide repeats that might be mutated in cancers with microsatellite instability (MSI). Frameshift mutations in a repeat of MLL3 have been found in colorectal cancers (CRC), but there is no frameshift mutation data of the other genes. In this study, we analyzed these repeats in 32 gastric cancers (GC) with high MSI (MSI-H), 59 GC with low MSI (MSI-L)/stable MSI (MSS), 40 CRC with MSI-H and 59 CRC with MSI-L/MSS by single-strand conformation polymorphism and DNA sequencing. We also analyzed MLL3 expression in GC and CRC tissues using immunohistochemistry. We found MLL, MLL2, MLL3 and MLL5 frameshift mutations in two (one GC and one CRC), three (one GC and two CRC), 17 (14 GC and three CRC) and six (four GC and two CRC) cancers, respectively. They were detected exclusively in MSI-H cancers, but not in MSI-L/MSS cancers. All of the cancers with MLL3 mutations showed loss of MLL3 expression, and their values were significantly lower than in those without MLL3 mutation (50.9\%). Of note, the GC with MSI-H had significantly higher incidences in both MLL mutations and MLL3 expression loss than the CRC with MSI-H. Our data indicate that frameshift mutations of MLL genes and loss of expression of MLL3 protein are common in GC and CRC with MSI-H.
\end{abstract}

Key words: MLL, frameshift mutation, MLL protein expression, cancer, microsatellite instability

Mixed lineage leukemia ( $M L L)$ genes include $M L L, M L L 2$, MLL3, MLL4 and MLL5, and encode proteins that act as histone methyltransferases [1-3]. They contain multiple domains in common, including Su(var)3-9, Enhancer-of-zeste, Trithorax (SET), plant homeodomain (PHD) zinc finger and DNA-binding domains (AT hook, Bromo and CXXC domains) [3]. The MLL proteins regulate histone 3- lysine 4 (H3K4) methylation, a modification associated with transcriptionally active genes [1]. MLL is a prototype of the $M L L$ genes and is the best studied among them [2]. MLL is essential for proper maintenance of $H O X$ gene expression during hematopoiesis and embryonic development [4-6]. The $M L L$ gene is frequently involved in chromosomal translocations associated with acute leukemias [2, 7-9]. Although nomenclature of the $M L L$ gene came from its function in hematopoiesis and its alterations in leukemias, it is ubiquitously expressed in most tissues [10]. Also, expressions of other MLL genes are identified not only in hematopoietic cells, but also in non-hematopoietic tissues [11-14]. Germline mutations of MLL2 gene are associated with Kabuki syndrome, a multiple malformation disorder [15]. Somatic mutations of the MLL2 gene have also been identified in medulloblastomas and lymphomas [16, 17]. Somatic mutations of MLL3 gene have been found in colorectal cancers (CRC) $[18,19]$. An earlier study found missense mutations of MLL3, while another study reported absence of MLL3 missense mutation in CRC [19, 20]. MLL4 gene is amplified in glioblastomas and pancreatic cancers [21]. These data suggest that mutational and expressional alterations of $M L L$ genes are implicated in diverse human malignancies. 
In a public genome database (http://genome.cse.ucsc. edu/), we found that human $M L L$ genes ( $M L L, M L L 2, M L L 3$, $M L L 4$ and MLL5) have mononucleotide repeats in the coding sequences that could be targets for frameshift mutation in cancers with microsatellite instability (MSI). Frameshift mutations of genes containing mononucleotide repeats are features of gastric (GC) and CRC with microsatellite instability (MSI) [22]. It is possible that frameshift mutations of the MLL-encoding genes could cause alterations of MLL functions and contribute to cancer pathogenesis in the cancers with MSI. However, frameshift mutations among these genes are known only in the MLL3 in CRC [18]. In this study, we used tumors that had already been evaluated their MSI status by a well developed criteria. With these tumor tissues, we explored whether the MLL genes are somatically mutated in GC and CRC with MSI.

\section{Materials and methods}

Tissue samples. For the mutation analysis, methacarnfixed tissues of sporadic $91 \mathrm{GC}$ and 99 CRC were used in this study. All of the cancer patients were Koreans. The GC consisted of 32 with high MSI (MSI-H), 14 with low MSI (MSI-L) and 45 with stable MSI (MSS). The CRC consisted of 40 with MSI-H, 14 with MSI-L and 45 with MSS. According to the NCI criteria tumors may be characterized as: MSI-H, if two or more of the five markers show instability, and MSI-L, if only one of the five markers shows instability by evaluating a panel of five validated microsatellites [23]. Previously we classified the GC and CRC specimens with these criteria. The pathologic features of the GC and CRC are summarized in Table 1. Approval for this study was obtained from the Institutional Review Board of Catholic University of Korea. Tumor cells and corresponding normal cells from the same patients were selectively procured from hematoxylin and eosin-stained slides using a 30G1/2 hypodermic needle affixed to a micromanipulator, as described previously $[24,25]$. DNA extraction was performed by a modified single-step DNA extraction method $[24,25]$.
Single strand conformation polymorphism (SSCP) analysis and genomic sequencing. MLL exon 3 (A7 and C7 repeats), MLL2 exon 10 (C7), MLL3 exon 38 (A9 and A7), MLL4 exon 3 (C7 and C7), MLL5 exon 8 (A7), MLL5 exon 14 (A7) and MLL5 exon 20 (A7) have mononucleotide repeats in their coding sequences. Genomic DNA from the microdissected cells was isolated, and was amplified by polymerase chain reaction (PCR) with 10 specific primer pairs (Table 2). Radioisotope ([32 $\mathrm{P}] \mathrm{dCTP})$ was incorporated into PCR products for detection by autoradiography. Procedures of PCR and SSCP analysis were performed as described previously $[24,25]$. After SSCP, mobility shifts on the SSCP gels (FMC Mutation Detection Enhancement system; Intermountain Scientific, Kaysville, UT) were determined by visual inspection. Direct DNA sequencing reactions were performed in the cancers with the mobility shifts in the SSCP. Sequencing of the PCR products was carried out using a capillary automatic sequencer (3730 DNA Analyzer, Applied Biosystem, Carlsbad, CA, USA). When mutations in the $M L L$ genes were suspected by SSCP, analysis of an independently isolated DNA from another tissue block of the same patients was performed to exclude potential artifacts originated from PCR.

Immunohistochemistry. Using the sections from GC and CRC tissues, immunohistochemistry for MLL3, which showed most frequent mutations, was performed in this study. The tissues consisted of $32 \mathrm{GC}$ and $40 \mathrm{CRC}$ with MSI-H, and 59 GC and 59 CRC with MSI-L/MSS. We used DAKO REAL EnVision System (DAKO, Glostrup, Denmark) for human MLL3 (Abcam, Cambridge, UK; dilution 1/50). After deparaffinization, heat-induced epitope retrieval was conducted by immersing the slides in Coplin jars filled with $10 \mathrm{mmol} / \mathrm{L}$ citrate buffer ( $\mathrm{pH}$ 6.0) and boiling the buffer for $30 \mathrm{~min}$ in a pressure cooker (Nordic Ware, Minneapolis, MN, USA) inside a microwave oven at $700 \mathrm{~W}$. The immunohistochemical procedure was performed as described previously [26]. The reaction products were developed with diaminobenzidine and counterstained with hematoxylin. By visual inspection under light microscope, tumors were interpreted as positive when $20-100 \%$ of the cells

Table 1. Summary of pathologic features of the gastric and colorectal cancers.

\begin{tabular}{|c|c|c|c|c|c|c|c|c|c|}
\hline \multicolumn{5}{|c|}{ No. of Gastric carcinomas } & \multicolumn{5}{|c|}{ No. of Colorectal carcinomas } \\
\hline & & $\begin{array}{l}\text { MSI-H } \\
(\mathbf{n}=32)\end{array}$ & $\begin{array}{l}\text { MSI-L } \\
(n=14)\end{array}$ & $\begin{array}{c}\text { MSS } \\
(n=45)\end{array}$ & & & $\begin{array}{l}\text { MSI-H } \\
(n=40)\end{array}$ & $\begin{array}{l}\text { MSI-L } \\
(n=14)\end{array}$ & $\begin{array}{c}\text { MSS } \\
(n=45)\end{array}$ \\
\hline \multirow[t]{4}{*}{ TNM } & I & 12 & 5 & 13 & TNM & I & 6 & 2 & 7 \\
\hline & II & 13 & 5 & 20 & & II & 14 & 4 & 16 \\
\hline & III & 6 & 3 & 10 & & III & 17 & 7 & 18 \\
\hline & IV & 1 & 1 & 2 & & IV & 3 & 1 & 4 \\
\hline \multirow[t]{4}{*}{ Lauren's subtype } & Diffuse & 16 & 8 & 22 & $\begin{array}{c}\text { Location } \\
\text { (colon) }\end{array}$ & Cecum & 6 & $\mathbf{0}$ & $\mathbf{0}$ \\
\hline & Intestinal & 13 & 5 & 18 & & Ascending & 22 & 2 & 2 \\
\hline & Mixed & 3 & 1 & 5 & & Transverse & 9 & 2 & 2 \\
\hline & & & & & & Descending \& sigmoid & 3 & 4 & 17 \\
\hline
\end{tabular}


Table 2. Primer sequences of the MLL genes used in this study

\begin{tabular}{|c|c|c|c|}
\hline Gene & Sequences & Size (bp) & Annealing temperature $\left({ }^{\circ} \mathrm{C}\right)$ \\
\hline \multirow{2}{*}{$M L L$ Exon 3-1 } & F: 5'-CCTTCCCTGGAGTAAAAATC-3’ & \multirow{2}{*}{132} & \multirow{2}{*}{49} \\
\hline & R: 5'- TAATCTTTGTGGCTTGCTG-3‘ & & \\
\hline \multirow{2}{*}{$M L L$ Exon 3-2 } & F: 5'-ACAAGAAGTGGAAGGCTTAG-3’' & \multirow{2}{*}{150} & \multirow{2}{*}{52} \\
\hline & R: 5'-AGACTGAGTCAGGGAATGAG -3' & & \\
\hline \multirow{2}{*}{ MLL2 Exon 10} & F: 5'-TCTGTTCCCACCATTTGAAGAG-3’ & \multirow{2}{*}{169} & \multirow{2}{*}{58} \\
\hline & R: 5'-GGATAGGCGCGATACCTCA-3‘ & & \\
\hline \multirow{2}{*}{ MLL3 Exon 38-1 } & F: 5‘-GCATGTTTAATGAGGAACTA-3’ & \multirow{2}{*}{126} & \multirow{2}{*}{47} \\
\hline & R: 5'-GTGGTGAATGTTTATCAGAG-3‘ & & \\
\hline \multirow{2}{*}{ MLL3 Exon 38-2 } & F: 5'-AATGAGGTAAAAACGGAAGT-3’ & \multirow{2}{*}{134} & \multirow{2}{*}{49} \\
\hline & R: 5'-TCATTTAGGTCTGAGTGAGC-3‘ & & \\
\hline \multirow{2}{*}{ MLL4 Exon 3-1 } & F: 5'-TTGATCCATCTCCCCACAAC-3’ & \multirow{2}{*}{151} & \multirow{2}{*}{58} \\
\hline & R: 5‘-CTTCCTCACCCCGTTTCC-3‘ & & \\
\hline \multirow{2}{*}{ MLL4 Exon 3-2 } & F: 5'-CCGCTCCTCCCGTGTCATC-3’ & \multirow{2}{*}{148} & \multirow{2}{*}{60} \\
\hline & R: 5‘-TGGAGAGGGGACTGGTGCTG-3‘ & & \\
\hline \multirow{2}{*}{ MLL5 Exon 8} & F: 5'-TGCTTCAAGAGTTTCCAAAG-3’ & \multirow{2}{*}{134} & \multirow{2}{*}{49} \\
\hline & R: 5'-AGTTCCCTATCCGCTATCC-3` & & \\
\hline \multirow{2}{*}{ MLL5 Exon 14} & F: 5'-AGAGTGCCCTGTTCTAAAAC-3’ & \multirow{2}{*}{154} & \multirow{2}{*}{49} \\
\hline & R: 5'-GGTCGTTCCTTCACAATC-3‘ & & \\
\hline \multirow{2}{*}{ MLL5 Exon 20} & F: 5'- AAAGTCATAACTGCCATTGT -3’ & \multirow{2}{*}{162} & \multirow{2}{*}{47} \\
\hline & R: $5^{\circ}$ - ACCGAATCTAGCAACTGAT -3‘ & & \\
\hline
\end{tabular}

showed moderate to intense staining in cytoplasm or nucleus, and as negative when $0-19 \%$ of the cells showed no or weak or moderate or intense staining by immunohistochemistry. Intensity of MLL3 immunostaining was interpreted as positive or negative independently by two pathologists. The immunostaining was judged to be specific by absence of consistent immunostaining of cells with replacement of primary antibody with the blocking reagent and reduction of immunostaining intensity as dilution of the antibody was increased. For the statistical analysis of the immunohistochemical data, we used Fisher's exact test and $\chi^{2}$ test.

\section{Results}

MLL gene mutations. Out of 10 evaluated mononucleotide repeats in $91 \mathrm{GC}$ and $99 \mathrm{CRC}$, we found aberrant bands in two cases of $M L L$ exon 3 (C7), three cases of $M L L 2$ exon 10 , 16 cases of $M L L 3$ exon 38 (A9), one case of MLL3 exon 38 (A7), one case of MLL5 exon 8, one case of MLL5 exon 14 and four cases of MLL5 exon 20 (Figure 1; Table 3). DNA from normal tissues from the same patients showed no evidence of the mutation in SSCP, indicating the mutations had risen somatically (Figure 1A). Direct DNA sequencing analysis of

Table 3. Summary of the frameshift mutations in the gastric and colorectal cancers with MSI

\begin{tabular}{|c|c|c|c|c|c|c|}
\hline Gene & Location & $\begin{array}{l}\text { Repeats } \\
\text { (wild type) }\end{array}$ & $\begin{array}{l}\text { Repeats } \\
\text { (Mutation) }\end{array}$ & $\begin{array}{l}\text { MSI status of the } \\
\text { mutation cases (n) }\end{array}$ & $\begin{array}{c}\text { Incidence in cancers with } \\
\text { MSI-H (\%) }\end{array}$ & $\begin{array}{c}\text { Nucleotide change } \\
\text { (predicted amino acid change) }\end{array}$ \\
\hline$M L L$ & Exon 3 & $\mathrm{C} 7$ & C6 & MSI-H (2) & $\begin{array}{c}\text { Gastric: } 1 / 32(3.1) \\
\text { Colorectal: } 1 / 40(2.5)\end{array}$ & c.2318delC (p.Ala773ArgfsX8) \\
\hline \multirow[t]{2}{*}{$M L L 2$} & \multirow[t]{2}{*}{ Exon 10} & $\mathrm{C} 7$ & C6 & MSI-H (2) & $\begin{array}{c}\text { Gastric: } 1 / 32(3.1) \\
\text { Colorectal: } 1 / 40(2.5)\end{array}$ & c. 1940delC (p.Pro647HisfsX283) \\
\hline & & C7 & $\mathrm{C} 8$ & MSI-H (1) & Colorectal: $1 / 40(2.5)$ & c.1940insC (p.Pro648ThrfsX2) \\
\hline \multirow{4}{*}{$M L L 3$} & \multirow{4}{*}{ Exon 38} & A9 & A8 & MSI-H (12) & $\begin{array}{c}\text { Gastric: } 9 / 32(28.1) \\
\text { Colorectal: } 3 / 40(7.5)\end{array}$ & c.8390delA (p.Lys2797ArgfsX26) \\
\hline & & A9 & A7 & MSI-H (2) & Gastric: $2 / 32(6.3)$ & c.8389_8390delAA (p.Lys2797GlyfsX11) \\
\hline & & A9 & $\mathrm{A} 10$ & MSI-H (2) & Gastric: $2 / 32(6.3)$ & c.8390insA (p.Glu2798GlyfsX11) \\
\hline & & A7 & A6 & MSI-H (1) & Gastric: $1 / 32(3.1)$ & c.8525insA (p.Asn2842LysfsX2) \\
\hline \multirow{3}{*}{ MLL5 } & Exon 8 & A7 & A6 & MSI-H (1) & Gastric: $1 / 32(3.1)$ & c.691delA (p.Ser231AlafsX73) \\
\hline & Exon 14 & A7 & A6 & MSI-H (1) & Colorectal: $1 / 40(2.5)$ & c.1482delA (p.Asp495ThrfsX26) \\
\hline & Exon 20 & A7 & A6 & MSI-H (4) & $\begin{array}{c}\text { Gastric: } 3 / 32(9.4) \\
\text { Colorectal: } 1 / 40(2.5)\end{array}$ & c.2619delA (p.Lys873AsnfsX8 \\
\hline
\end{tabular}


A.

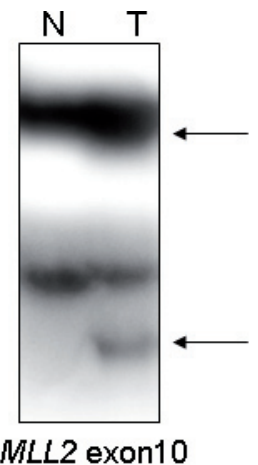

B. Normal

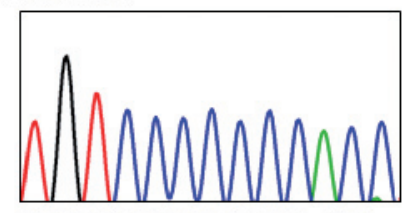

TGTCCCCCCCACC (C7)

Tumor

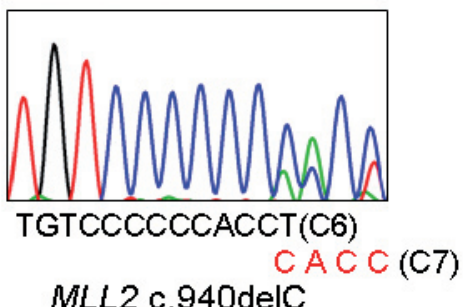

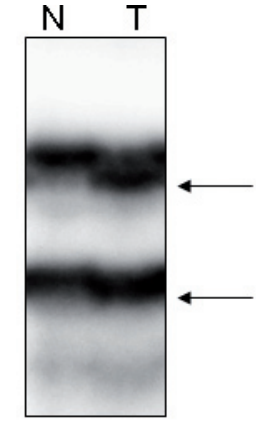

MLL3 exon 38

Normal

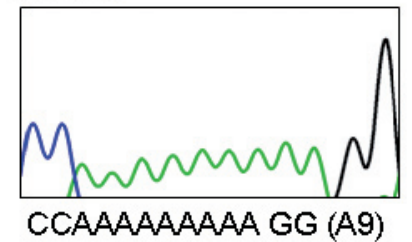

Tumor

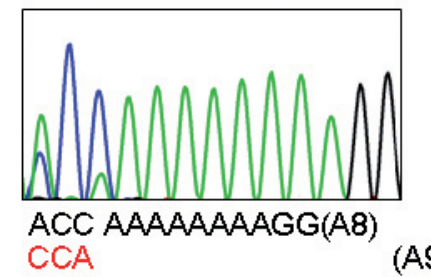

MLL3 c.8390delA

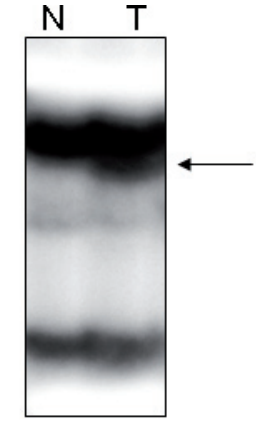

$M L L 5$ exon 8

Normal

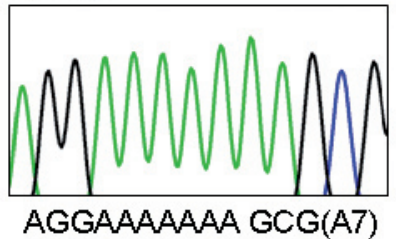

Tumor

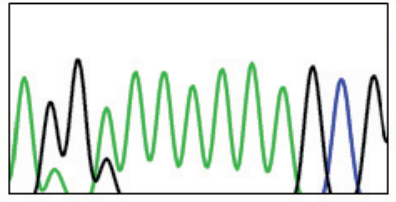

AAGGAAAAAA GCG(A6) AGGA

MLL5 c.691delA
(A7)

Figure 1. Representative SSCP and DNA sequencing of $M L L 2, M L L 3$ and $M L L 5$ genes in the cancers. A: In the SSCP, the arrows (Lane T) indicate aberrant bands compared to the SSCP from normal tissues (N). B: Direct DNA sequencing analyses of $M L L 2$ (left), $M L L 3$ (middle) and $M L L 5$ (right) show heterozygous deletions of a nucleotide in tumor tissue as compare to normal tissues.

the cancer tissues with the aberrantly migrating bands led to identification of $M L L, M L L 2, M L L 3$ and $M L L 5$ gene mutations in two, three, 17 and six cancers, respectively (Table 3). All of the mutations were interpreted as heterozygous according to the SSCP and direct sequencing analyses (Figure 1). All of the 28 mutations were deletion or insertion mutations of the bases in the repeats that could cause the premature stop codon, which leads to the termination of translation (Table 3 ). There was no aberrant band in the SSCP of MLL4 gene.

All of the mutations were detected in the cancers with MSI$\mathrm{H}$ (Table 3), but not in those with MSI-L or MSS. There were statistical differences between the frequencies of the mutations together in the cancers with MSI-H (28/72) and MSI-L $(0 / 28)$ (Fisher's exact test, $p<0.001)$, and those with MSI-H $(28 / 72)$ and MSS $(0 / 90)$ (Fisher's exact test, $p<0.001)$. Of the 32 GC with MSI-H, 16 cancers harbored one mutation each and two cancers harbored two mutations (18/32; 56.3\%). Of the $40 \mathrm{CRC}$ with MSI-H, six cancers harbored one mutation each and one cancer harbored two mutations (7/40; 17.5\%). The GC with MSI-H had a significantly higher incidence in MLL mutations than the CRC with MSI-H (Fisher's exact test, $p=0.001)$. At individual gene level, there were significant differences of mutation frequencies of MLL3 (Fisher's exact test, $p<0.001$ ) and MLL5 (Fisher's exact test, $p=0.003$ ) genes between cancers with MSI-H and non-MSI-H. There was no significant association of the mutations with the clinicopathologic data of the patient (age, sex, stage, and metastasis). There was no correlation between histological features of the tumors (histologic grade, subtypes, mucinous histology, medullary pattern and tumor-infiltrating lymphocytes) and the presence of the mutations, either.

Expression of MLL3 protein. We used immunohistochemistry to examine expression of MLL3 that had been found to be mutated most among the MLL genes in the cancers analyzed. We analyzed MLL3 protein expression in 32 GC and 40 CRC with MSI-H, and 59 GC and 59 CRC with MSI-L/MSS. Immunopositivity for MLL3 was observed in 10 (31.3\%) of the GC and 18 (45.0\%) of the CRC with MSI-H (Figure 2; Table 4). Of the 17 cancers with MLL3 frameshift mutations (Table 4), none of them showed positive MLL3 immunostaining, and there was a significant difference of MLL3 immunostaining between MSI-H cancers harboring 
mutations in MLL3 mutations and the MSI-H cancers that have not acquired mutations in MLL3 (Fisher's exact test, $p<0.001)$. There was a significant difference of MLL3 immunopositivity between the GC with MSI-H and the GC with MSI-L/MSS (Fisher's exact test, $p<0.05$ ), but not between the CRC with MSI-H and the CRC with MSI-L/MSS (Fisher's exact test, $p>0.05$ ) (Table 4 ).
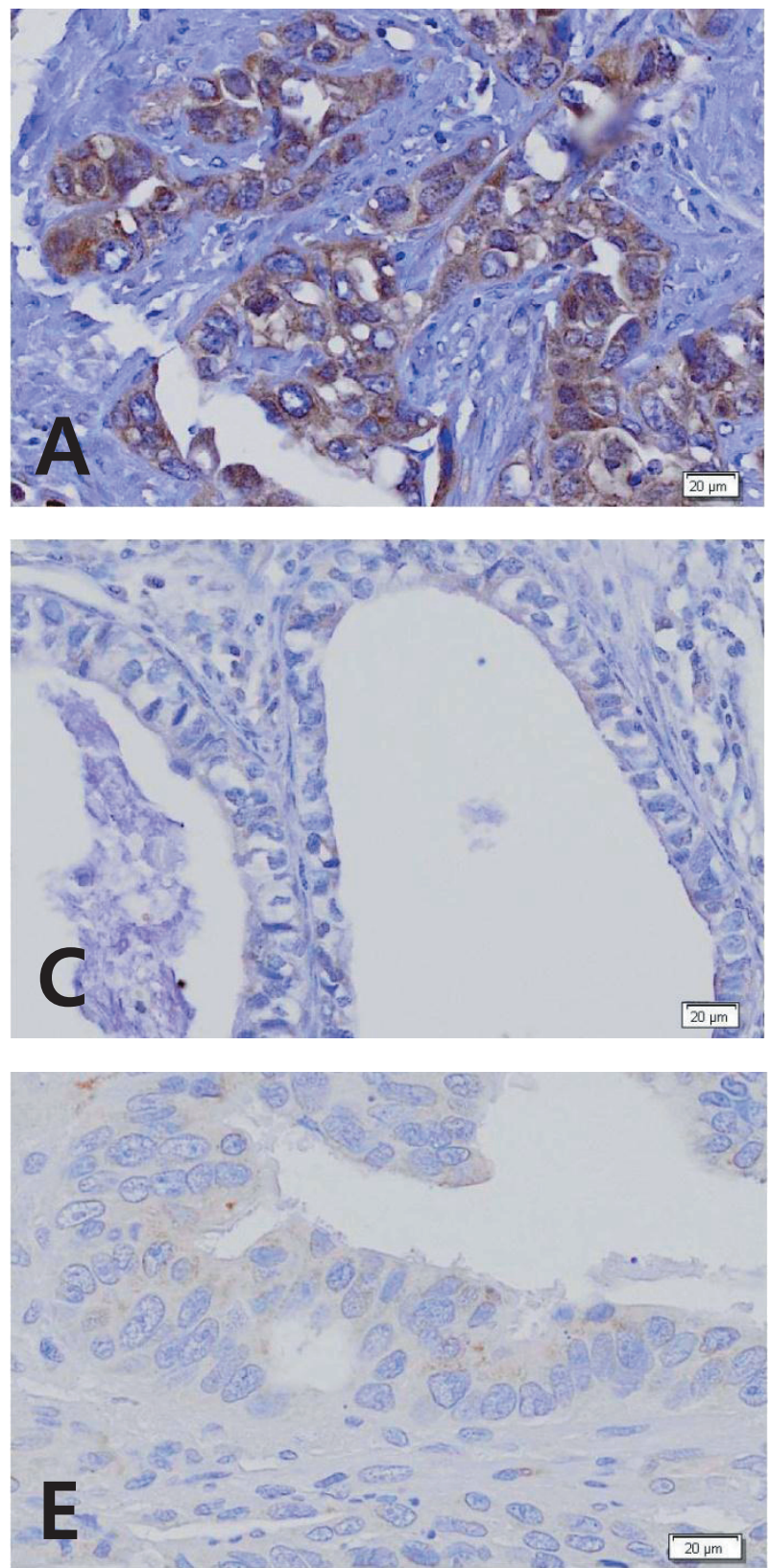

\section{Discussion}

Based on the earlier reports that MLL proteins are critically involved in chromatin modification and are implicated in the pathogenesis of human diseases [1-9], we attempted to determine whether somatic frameshift mutation of $M L L$ genes is present in GC and CRC tissues that are the most common
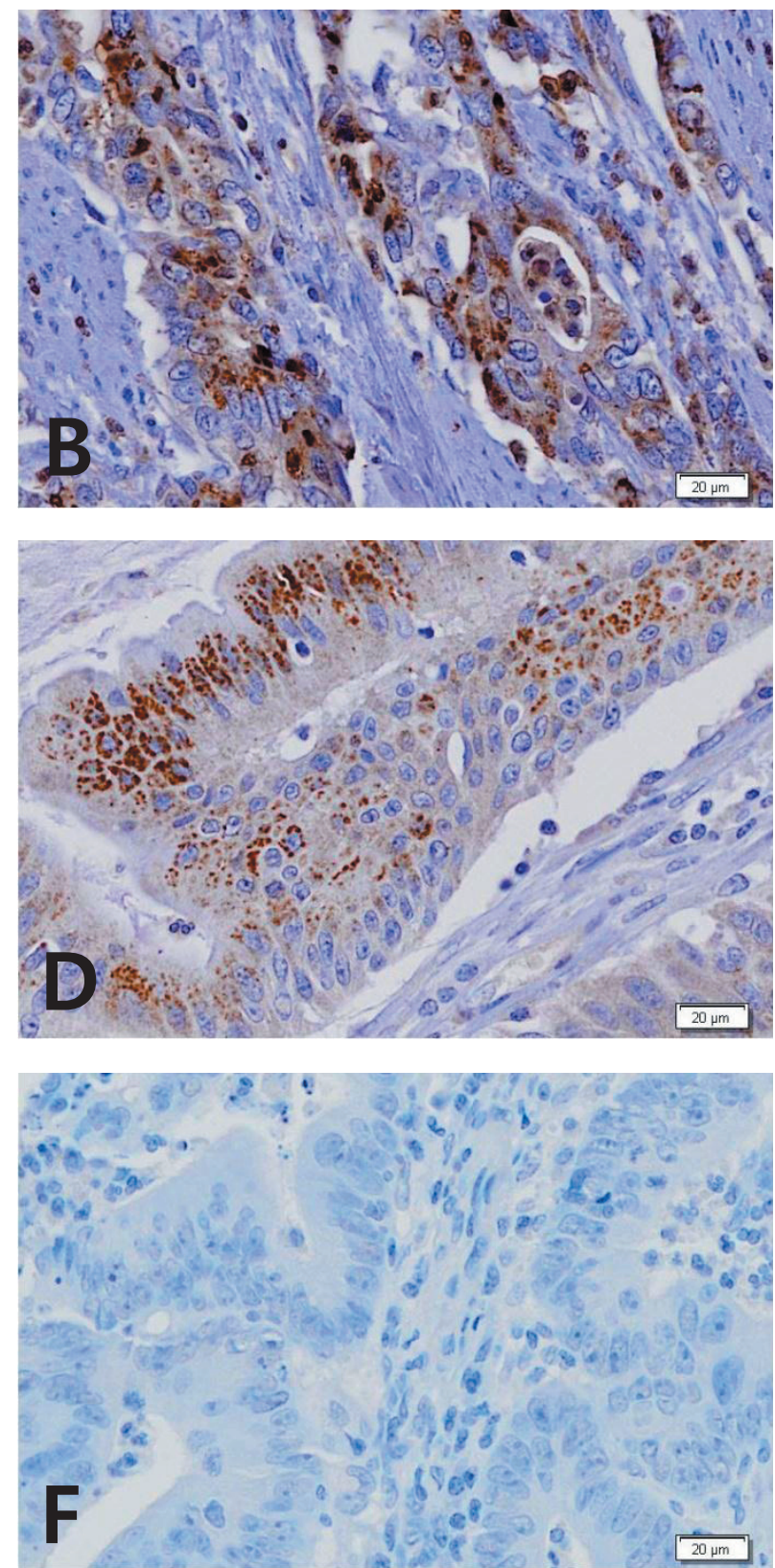

Figure 2. Visualization of MLL3 expression in gastric and colorectal cancer tissues with MSI-H by immunohistochemistry. A: A gastric cancer without mutation in evaluated A9 repeat shows MLL3 immunostaining in both cytoplasm and nuclei of the cancer cells. B: Another gastric cancer with a frameshift mutation in MLL3 shows MLL3 immunostaining mainly in cytoplasm of the cancer cells. C: In a gastric cancer with a frameshift mutation in MLL3, the cancer cells are negative for MLL3 immunostaining. D: A colon cancer without mutation in evaluated A9 repeat shows MLL3 immunostaining mainly in cytoplasm of the cancer cells. E: In another colon cancer without mutation in evaluated A9 repeat, the cancer cells are negative for MLL3 immunostaining. F: A negative control of the immunostaining with omission of primary antibody in a colon cancer shows no MLL3 immunostaining. (Scale bars: 20 um) 
cancers in gastrointestinal tract. We found frameshift mutations of $M L L, M L L 2, M L L 3$ and MLL5 genes in both GC and CRC. These mutations were found exclusively in the cancers with MSI-H, but not in those with MSI-L or MSS, indicating all but one $M L L$ genes are altered in the GC and CRC with MSI-H by somatic mutations.

Among the $M L L$ genes with somatic mutations in the present study, all except MLL3 mutations were novel mutations. An earlier study documented that CRC with MSI-H harbored a type of MLL3 frameshift mutation (c.8390delA) in $24.5 \%$ of the cases [18]. In our study, we found MLL3 frameshift mutations in GC with MSI that had not been reported yet. In addition to the one base deletion (c.8390delA), we found one base insertion (c.8390insA) and two base deletion (c.8389_8390delAA) (Table 3). We found also frameshift mutation in the other repeat of MLL3 (c.8525insA). We found MLL3 frameshift mutations in $7.5 \%$ of CRC with MSI, which were in contrast with other study where the mutations had been detected in 24.5\% of CRC [18] (Fisher's exact test, $p=$ $0.024)$. By contrast, the incidence in GC was not statistically different (Fisher's exact test, $p>0.05$ ). However, the background mechanisms of such differences between our data and the earlier data are unclear. Collectively, our data indicate that MLL3 frameshift mutation may be common not only in CRC with MSI, but also in GC with MSI, and suggest that $M L L 3$ frameshift mutation might contribute to pathogenesis of cancers with MSI.

$M L L$ gene is altered by rearrangements in leukemias and contributes to leukemogenesis [7-9]. Because such rearrangements have not been found in solid cancers and MLL gene expression is not limited to hematopoietic system, we hypothesized that $M L L$ gene could be altered by other mechanisms. The frameshift mutations identified in this study would lead to premature stops of amino acid syntheses in MLL proteins and hence resembles a typical loss-of-function mutation [27-29]. Because both MLL3 and MLL5 are known to perform tumor suppressor functions [30,31], the frameshift mutations may inhibit their tumor suppressor functions and contribute to tumorigenesis. By contrast, tumor-related functions of MLL2 and MLL4 are largely unknown. Rather, MLL2 expression is overexpressed in colon and breast cancers [32], and MLL4 gene is amplified in glioblastoma and pancreatic cancers [21]. These data suggest a possibility that hyperfunction of MLL2 and MLL4 is involved in cancer pathogenesis. It remains to be clarified, how the functions of MLL2 and MLL4 are different in GC and CRC with MSI, and what the consequence of the mutations in their pathogenesis is.

All of the five MLL genes have SET domains in the C-terminals, which are predicted to be removed by the frameshift mutations in MLL, MLL2 and MLL3 genes. The SET-domain protein methyltransferase superfamily includes all but one of the proteins known to be essential for histone methylation that is important in the regulation of chromatin structure and gene expression [33]. It becomes apparent that the histone methylation can be perturbed in disease. For example,
Table 4. Summary of MLL3 expression in gastric and colorectal cancers.

\begin{tabular}{lc}
\hline & $\begin{array}{c}\text { Positive MLL3 } \\
\text { expression (\%) }\end{array}$ \\
\hline GC with MSI-H $(\mathbf{n}=32)$ & $10(31.3)$ \\
CRC with MSI-H $(\mathbf{n}=40)$ & $18(45.0)$ \\
GC with MSI-L/MSS $(\mathbf{n}=59)$ & $30(50.8)$ \\
CRC with MSI-L/MSS (n=59) & $28(47.5)$ \\
MSI-H GC and CRC with MLL3 mutation $(n=17)$ & $0(0)$ \\
MSI-H GC and CRC without $M L L 3$ mutation $(n=55)$ & $28(50.9)$ \\
\hline
\end{tabular}

a SET-domain protein SMYD3 is upregulated in colorectal and liver cancers, and its histone H3 K4 methyltransferase activity activates oncogenes associated with cell cycle [34]. Another SET domain-containing protein EZH2 is involved in metastasis of prostate and breast cancers [35]. Through our study here, we could accumulate evidence that other SET-containing genes ( $M L L$ genes) were also altered in GC and CRC. In the affected cancers, how the loss of SET domains is involved in cancer pathogenesis (cancer types (GC/ CRC) or MSI (MSI$\mathrm{H})$ ) remains to be explained in future studies.

We observed that MLL3 immunostainings were very weakly or not detectable in all of the cancers with MLL3 frameshift mutations (Table 4). Because the antibody against MLL3 had been raised by a peptide immunogen within amino acid residues 3471-3501 that would be removed by the $M L L 3$ frameshift mutations detected in the present study, the mutated MLL3 proteins might not be detected in the cancer cells by the antibody. Mutations involve either one of the two alleles (heterozygous mutation) or both of the two alleles (homozygous mutation). SSCP and direct sequencing of MLL3 in the mutated cases showed that all frameshift mutations appeared heterozygous (Figure 1), suggesting that one of the alleles was intact. Although it was possible that normal cell contamination made it difficult to conclude the mutations were heterozygous, use of a microdissection method that had been proven to procure tumor cells with nearly being devoid of normal cell contamination [36] led us to conclude that the mutations were heterozygous. In these cases, loss of the MLL3 immunostaining in the cancers might be caused by the frameshift mutation in one allele and by the other gene silencing mechanisms in the second allele. Another possibility for the absence is that quantity of MLL3 expression from one allele might not be enough to be detected by the antibody in the immunohistochemistry. Of note, about half (27/55) of tumors with wild-type MLL3 showed loss of MLL3 expression by the immunohistochemistry (Table 4). These data suggest a possibility that loss of MLL3 expression in GC and CRC may be affected not only by frameshift mutations in the repeats, but also by other mechanisms such as epigenetic mechanisms or other somatic mutations besides the frameshift mutations.

Alteration of histone modification in chromatin has long been recognized as an important step in cancer development. 
However, exact mechanisms for such deregulation are partly known. In the present study, we found somatic mutations of $M L L$ genes in human GC and CRC tissues. However, the consequences of such frameshift mutations in cancer development remain unknown. It is imperative that functional studies on the mutated genes and their products using in vitro models and animal models should be further performed. Also, to see whether mutations and losses of expression of MLL genes are common features of cancers. Mutations and expression status of the genes should be further extended even in other cancers.

Acknowledgements: This work was supported by funding from National Research Foundation of Korea (2012047939).

\section{References}

[1] POPOVIC R, ZELEZNIK-LE NJ. MLL: how complex does it get? J Cell Biochem 2005; 95: 234-242. http://dx.doi. org/10.1002/jcb.20430

[2] MARSCHALEK R. Mechanisms of leukemogenesis by MLL fusion proteins. Br J Haematol 2011; 152: 141-154. http:// dx.doi.org/10.1111/j.1365-2141.2010.08459.x

[3] SMITHE, LIN C, SHILATIFARD A. The super elongation complex (SEC) and MLL in development and disease. Genes Dev 2011; 25: 661-672. http://dx.doi.org/10.1101/gad.2015411

[4] KRUMLAUF R. Hox genes in vertebrate development. Cell 1994; 78: 191-201. http://dx.doi.org/10.1016/00928674(94)90290-9

[5] ORLANDO V, JANE EP, CHINWALLA V, HARTE PJ, PARO R. Binding of trithorax and Polycomb proteins to the bithorax complex: dynamic changes during early Drosophila embryogenesis. EMBO J 1998; 17: 5141-5150. http://dx.doi. org/10.1093/emboj/17.17.5141

[6] MILLER T, KROGAN NJ, DOVER J, ERDJUMENT-BROMAGE H, TEMPST P et al. COMPASS: a complex of proteins associated with a trithorax-related SET domain protein. Proc Natl Acad Sci U S A 2001; 98: 12902-12907. http://dx.doi. org/10.1073/pnas.231473398

[7] MOHAN M, LIN C, GUEST E, SHILATIFARD A. Licensed to elongate: a molecular mechanism for MLL-based leukaemogenesis. Nat Rev Cancer 2010; 10: 721-728. http://dx.doi. org/10.1038/nrc2915

[8] TKACHUK DC, KOHLER S, CLEARY ML. Involvement of a homolog of Drosophila trithorax by 11q23 chromosomal translocations in acute leukemias. Cell 1992; 71: 691-700. http://dx.doi.org/10.1016/0092-8674(92)90602-9

[9] THIRMAN MJ, GILL HJ, BURNETT RC, MBANGKOLLO D, MCCABE NR et al. Rearrangement of the MLL gene in acute lymphoblastic and acute myeloid leukemias with 11q23 chromosomal translocations. N Engl J Med 1993; 329: 909-914. http://dx.doi.org/10.1056/NEJM199309233291302

[10] BUTLER LH, SLANY R, CUI X, CLEARY ML, MASON DY. The HRX proto-oncogene product is widely expressed in human tissues and localizes to nuclear structures. Blood 1997; 89: 3361-3370.
[11] FITZGERALD KT, DIAZ MO. MLL2: A new mammalian member of the trx/MLL family of genes. Genomics 1999; 59: 187-192. http://dx.doi.org/10.1006/geno.1999.5860

[12] RUAULT M, BRUN ME, VENTURA M, ROIZĖS G, DE SARIO A. MLL3, a new human member of the TRX/MLL gene family, maps to 7q36, a chromosome region frequently deleted in myeloid leukaemia. Gene 2002; 284: 73-81. http://dx.doi. org/10.1016/S0378-1119(02)00392-X

[13] NAGASE T, ISHIKAWA K, NAKAJIMA D, OHIRA M, SEKI $\mathrm{N}$ et al. Prediction of the coding sequences of unidentified human genes. VII. The complete sequences of 100 new cDNA clones from brain which can code for large proteins in vitro. DNA Res 1997; 4: 141-150. http://dx.doi.org/10.1093/ dnares/4.2.141

[14] EMERLING BM, BONIFAS J, KRATZ CP, DONOVAN S, TAYLOR BR et al. MLL5, a homolog of Drosophila trithorax located within a segment of chromosome band 7q22 implicated in myeloid leukemia. Oncogene 2002; 21: 4849-4854. http://dx.doi.org/10.1038/si.onc.1205615

[15] NG SB, BIGHAM AW, BUCKINGHAM KJ, HANNIBAL MC, MCMILLIN MJ et al. Exome sequencing identifies MLL2 mutations as a cause of Kabuki syndrome. Nat Genet 2010; 42: 790-793. http://dx.doi.org/10.1038/ng.646

[16] PARSONS DW, LI M, ZHANG X, JONES S, LEARY RJ et al.javascript:AL_get(this, ,jour', ,J Biol Chem.'); The genetic landscape of the childhood cancer medulloblastoma. Science 2011; 331: 435-439. http://dx.doi. org/10.1126/science.1198056

[17] MORIN RD, MENDEZ-LAGO M, MUNGALL AJ, GOYA R, MUNGALL KL et al. Frequent mutation of histone-modifying genes in non-Hodgkin lymphoma. Nature 2011; 476: 298-303. http://dx.doi.org/10.1038/nature10351

[18] WATANABE Y, CASTORO RJ, KIM HS, NORTH B, OIKAWA R et al. Frequent alteration of MLL3 frameshift mutations in microsatellite deficient colorectal cancer. PLoS One 2011; 6: e23320. http://dx.doi.org/10.1371/journal. pone. 0023320

[19] SJOBLOM T, JONES S, WOOD LD, PARSONS DW, LIN J et al. The consensus coding sequences of human breast and colorectal cancers. Science 2006; 314: 268-274. http://dx.doi. org/10.1126/science.1133427

[20] AHN CH, YOO NJ, LEE JW, LEE SH, LEE SH. Absence of MLL3 mutations in colorectal carcinomas of Korean patients. APMIS 2007; 115: 859-860. http://dx.doi.org/10.1111/j.16000463.2007.apm 696.x

[21] HUNTSMAN DG, CHIN SF, MULERIS M, BATLEY SJ, COLLINS VP et al. MLL2, the second human homolog of the Drosophila trithorax gene, maps to $19 \mathrm{q} 13.1$ and is amplified in solid tumor cell lines. Oncogene 1999; 18: 7975-7984.

[22] IMAI K, YAMAMOTO H. Carcinogenesis and microsatellite instability: the interrelationship between genetics and epigenetics. Carcinogenesis 2008; 29: 673-680. http://dx.doi. org/10.1093/carcin/bgm228

[23] BOLAND CR, THIBODEAU SN, HAMILTON SR, SIDRANSKY D, ESHLEMAN JR et al. A National Cancer Institute Workshop on Microsatellite Instability for cancer detection and familial predisposition: development of international 
criteria for the determination of microsatellite instability in colorectal cancer. Cancer Res 1998; 58: 5248-5257.

[24] KIM YR, OH JE, KIM MS, KANG MR, PARK SW et al. Oncogenic NRF2 mutations in squamous cell carcinomas of oesophagus and skin. J Pathol 2010; 220: 446-451. http:// dx.doi.org/10.1002/path.2653

[25] LEE JW, SOUNG YH, KIM SY, LEE HW, PARK WS et al. PIK3CA gene is frequently mutated in breast carcinomas and hepatocellular carcinomas. Oncogene 2005; 24: 1477-1480. http://dx.doi.org/10.1038/sj.onc.1208304

[26] KIM MS, HUR SY, YOO NJ, LEE SH. Mutational analysis of FOXL2 codon 134 in granulosa cell tumour of ovary and other human cancers. J Pathol 2010; 221: 147-152. http://dx.doi. org/10.1002/path.2688

[27. AKIYAMA Y, IWANAGA R, ISHIKAWA T, SAKAMOTO K, NISHIN et al. Mutations of the transforming growth factor-beta type II receptor gene are strongly related to sporadic proximal colon carcinomas with microsatellite instability Cancer 1996; 78: 2478-2484. http://dx.doi.org/10.1002/(SICI)10970142(19961215)78:12<2478::AID-CNCR5>3.0.CO;2-G

[28] RAMPINO N, YAMAMOTO H, IONOV Y, LI Y, SAWAI $\mathrm{H}$ et al. Somatic frameshift mutations in the BAX gene in colon cancers of the microsatellite mutator phenotype. Science 1997; 275: 967-969. http://dx.doi.org/10.1126/ science.275.5302.967

[29] SCHWARTZ S JR, YAMAMOTO H, NAVARRO M, MAESTRO M, REVENTOS J et al. Frameshift mutations at mononucleotide repeats in caspase- 5 and other target genes in endometrial and gastrointestinal cancer of the microsatellite mutator phenotype. Cancer Res 1999; 59: 2995-3002.
[30] LEE J, KIM DH, LEE S, YANG QH, LEE DK et al. A tumor suppressive coactivator complex of p53 containing ASC-2 and histone H3-lysine-4 methyltransferase MLL3 or its paralogue MLL4. Proc Natl Acad Sci U S A 2009; 106: 8513-8518. http:// dx.doi.org/10.1073/pnas.0902873106

[31] DENG LW, CHIU I, STROMINGER JL. MLL 5 protein forms intranuclear foci, and overexpression inhibits cell cycle progression. Proc Natl Acad Sci U S A 2004; 101: 757-762. http://dx.doi.org/10.1073/pnas.2036345100

[32] NATARAJAN TG, KALLAKURY BV, SHEEHAN CE, BARTLETT MB, GANESAN N et al. Epigenetic regulator MLL2 shows altered expression in cancer cell lines and tumors from human breast and colon. Cancer Cell Int 2010; 10: 13. http://dx.doi.org/10.1186/1475-2867-10-13

[33] YEATES TO. Structures of SET domain proteins: protein lysine methyltransferases make their mark. Cell 2002; 111: 5-7.

[34] HAMAMOTO R, FURUKAWA Y, MORITA M, IIMURA Y, SILVA FP et al. SMYD3 encodes a histone methyltransferase involved in the proliferation of cancer cells. Nat Cell Biol 2004; 6: 731-740. http://dx.doi.org/10.1038/ncb1151

[35] MIN J, ZASLAVSKY A, FEDELE G, MCLAUGHLIN SK, RECZEK EE et al. An oncogene-tumor suppressor cascade drives metastatic prostate cancer by coordinately activating Ras and nuclear factor-kappaB. Nat Med 2010; 16: 286-294. http://dx.doi.org/10.1038/nm.2100

[36] LEE JY, DONG SM, KIM SY, YOO NJ, LEE SH et al. A simple, precise and economical microdissection technique for analysis of genomic DNA from archival tissue sections. Virchows Arch 1998; 433: 305-309. http://dx.doi.org/10.1007/ $\underline{\mathrm{s} 004280050253}$ 